\title{
CARACTERIZAÇÃO DA FERTILIDADE DE DOIS SOLOS DE MAMANGUAPE, ESTADO DA PARAÍBA. (1)
}

\author{
GILSON MOURA FILHO (2), JOSÉ PIRES DANTAS (3) \\ \& ALDO VILAR TRINDADE (4)
}

\section{RESUMO}

Foi conduzido no Centro de Ciências Agrárias da Universidade Federal da Paraíba, em casa-de-vegetação, um experimento utilizando-se amostras de dois solos do Município de Mamanguape, Estado da Paraíba (Areias Quartzosas Distróficas - AQd e Podzólico VermeIho Amarelo Distrófico - PVd), cultivados intensarnente com a cultura do abacaxi, objetivando caracterizar os nutrientes limitantes, através da diagnose por subtraçāo, usando o sogo granífero (Sorghum bicolor (L.) Moench. cv. ICAPAL), como planta indicadora. O experimento foi composto por quartorze tratamentos, por solo, sendo uma testemunha absoluta, um com todos os nutrientes $(\mathrm{N}, \mathrm{P}, \mathrm{K}, \mathrm{Ca}$, $\mathrm{Mg}, \mathrm{S}, \mathrm{B}, \mathrm{Cu}, \mathrm{Fe}, \mathrm{Mn}$, Mo e $\mathrm{Zn}$ ) e os demais tratamentos com todos os nutrientes menos o elemento em estudo. Os resultados obtidos em função da produção de matéria seca da parte aérea, mostraram que no solo AQd foram limitantes, em ordem decrescente, os seguintes nutrientes: fósforo, nịtrogênio, potássio, zinco e cálcio,e no PVd, fósforo, nitrogênio, potássio e cálcio. Para maior eficiência dos nutrientes a serem aplicados nesses solos, recomenda-se a prática da calagem.

(1) Trabalho apresentado no XXI Congresso Brasileiro de Cléncia do Solo, Campinas, Julho de 1987. Acelto para publicaçăo em 28 de novembro de 1990.

(2) Prof. Assistente, Departamento de Agronomia - CECA/UFAL. 57.080 - Maceió-AL.

(3) Prof. Adjunto, Departamento de Solos e Engenharia Rural - CCA/UFPB. 58.397 - Areia-PB

(4) Eng. Agrónomo. Estudante de Pós-Graduaçăo em Solos e Nutriçăo de Plantas - UFV. 36.570 - Viçosa - MG. 
Termos para indexação: diagnose por subtração, casa-de-vegetação, matéria seca e parte aérea.

\section{ABSTRACT}

\section{FERTILITY CARACTERIZATION OF TWO SOILS IN THE STATE OF}

\section{PARAIBA}

In order to caracterize the soils fertility in the state of Paraiba, two soils samples obtained from Mamanguape country were studied under greenhouse conditions by the missing element technique. These two soils were Red Yellow Podzolic-distrophic (pvD) and Quartz Sands-distrophic (AQd). Grain sorghum (Sorghum bicolor (L.) Moench. CV. ICAPAL) was used as the test plant. The experiment had fourteen treatments with three repetition arranged in a completely randomised design. The tretaments were: no nutrients; one with all the essential nutrients ( $\mathrm{N}, \mathrm{P}, \mathrm{K}, \mathrm{Ca}, \mathrm{Mg}, \mathrm{S}, \mathrm{B}, \mathrm{Cu}, \mathrm{Fe}$, $\mathrm{Mr}$, Mo e $\mathrm{Zn}$ ) and rest with one of these elements omitted. Dry matter weight of the aerial part was measured. The results in both types of soils (PVd and $A Q d$ ) showed a reduction of ry matter weight on those treatments where $\mathrm{N}, \mathrm{P}, \mathrm{K}$ and $\mathrm{Ca}$ were omitted. In the AQd soil type the omission of $\mathrm{Zn}$ also reduced the dry matter weight.

Index terms: missing element technique, greenhouse, dry matter and aerial part.

\section{INTRODUÇÃO}

Os solos do Município de Mamanguape, Estado da Paraíba, são intensamente cultivados com a cultura do abacaxi (Ananas comusus (L.) Merr.).

Com o uso constante, esses solos tornam-se improdutivos, havendo com isso, necessidade do conhecimento do comportamento dos nutrientes, a fim de que se faça uma adubação equilibrada e ecor.6́mica, fazendo com que os niveis de produtividade da cultura sejam elevados. 
A avaliação da fertilidade pelo método da "diagnose por subtração" constitui uma técnica rápida, válida e poderosa para diagnósticar deficiência de nutrientes nos solos (KILLIAN \& VELLY, 1964; CHAAMINADE, 1965; MARTINI, 1969; SHENKEL et alii, 1970; MOURA FILHO \& DANTAS, 1986).

Utilizando esse método, SANTOS (1980); ANDRADE FILHC et ali (1984); DINIZ (1984) e MOURA FILHO \& DANTAS (1986) constataram sérias deficiências de nitrogênio, fósforo, potássio, cálcio, enxofre, boro e cobre, em diversos solos da Paraíba.

$O$ objetivo do presente trabalho foi caracterizar os nutrientes limitantes em duas amostras de solos do Município de Mamanguape, Estado da Paraíba, através do método da diagnose por subração.

\section{MATEFIAL E MÉTODOS}

O ensaio foi conduzido em casa-de-vegetação, no Centro de Ciências Agrárias da Universidade Federal da Paraíba, usando amostras superficiais (até $20 \mathrm{~cm}$ de profundidade) de dois solos (Areias Quartzosas distróficas - AQd e Podzólico Vermelho Amarelo distrófico - PVd) do Município de Marnanguape, Estado da Paraíba. Estas amostras de solos foram secas ao ar, destorroadas e passadas em peneira de $2 \mathrm{~mm}$ de abertura. Porções de cada amostra de solo bem homogeneizadas foram submetidas as análises químicas e classificação textural (Quadro 1).

As amostras de solo foram acondicionadas em vasos plásticos, na proporção de $4 \mathrm{~kg}$ de solo/vaso. Foi feita uma calagem com $\mathrm{CaCO}_{3}$ p.a., sendo as quantidades calculadas conforme os teores de $\mathrm{Al}$ e $\mathrm{Ca}$ + Mg trocáveis (EMPRESA DE ASSISTÉNCIA TÉCNICA E EXTENSÃO RURAL DA PARAÍBA (1979). Após a aplicação do corretivo segui-se um período de incubação de 20 dias, com 0 teor de umidade mantido em torno de $80 \%$ da capacidace máxima de retenção de água. A testemunha absoluta e o tratamento com cmissão de cálcio rão receberam corretivo.

$O$ delinearrento experimental utilizado foi o inteiramente ao acaso, com quatorze tratamentos e três repetições, por solo. $O$ tratamento completo recebeu $\mathrm{N}, \mathrm{P}, \mathrm{K}, \mathrm{Ca}, \mathrm{Mg}, \mathrm{S}, \mathrm{B}, \mathrm{Cu}, \mathrm{Fe}, \mathrm{Mn}$, Mo e $\mathrm{Zn}$, sendo os demais tratamentos, com exceção da testemunha absoluta, constituídos pela omissão de um desses nutrientes de cada vez.

As soluções nutritivas foram adicionadas um dia antes do plantio a cada tratamento correspondente, deixando apenas $50 \%$ da dose de nitrogênio ( $\mathrm{NH}_{4} \mathrm{NC}_{3}$ ) para ser aplicada aos vinte dias após a emergência das plântulas. As doses e fontes de cada nutriente estão no Quadro 2. 
QUADRO 1 - Características químicas e classificação textural das amostras de solos. (1)

\begin{tabular}{|c|c|c|}
\hline Características & AQd & PVd \\
\hline $\mathrm{pH}$ em água $(1: 2,5)$ & 5,4 & 5,6 \\
\hline$P(\mu \mathrm{g} / \mathrm{cm})$ & 3,6 & 1,2 \\
\hline $\mathrm{K}(\mu \mathrm{g} / \mathrm{cm})$ & 24,0 & 24,0 \\
\hline $\mathrm{Ca}^{2+}+\mathrm{Mg}^{2+}($ meq $/ 100 \mathrm{~cm}) 3(3)$ & 1,75 & 1,75 \\
\hline $\mathrm{Al}^{3+}(\mathrm{meq} / 100 \mathrm{~cm}) 3(3)$ & 0,20 & 0,10 \\
\hline M.O. (\%) (4) & 0,70 & 0,80 \\
\hline Classificação textural (USDA) & Arenoso & Franco Arenoso \\
\hline Nec. de calagem ( $t / h a)$ & 0,45 & 0,65 \\
\hline
\end{tabular}

(1) Análises realizadas no Laboratório de Fertilidade do Solo do CCA/UFPB.

(2) Extrator Mehlich-1.

(3) Extrator KC1 $1 \mathrm{~N}$.

(4) Método Walkley-Black.

QUADRO 2-Doses e fontes dos nutrientes utilizados.

\begin{tabular}{|c|c|c|}
\hline Nutriente & ppm do substrato & Fonte \\
\hline Nitrogênio & 200 & $\mathrm{NH}_{4} \mathrm{NO}_{3}$ \\
\hline Fósforo & 200 & $\mathrm{NaH}_{2} \mathrm{PO}_{4} \cdot \mathrm{H}_{2} \mathrm{O}$ \\
\hline Potássio & 200 & $\mathrm{KCl}$ \\
\hline Cálcio & 50 & $\mathrm{CaCl}_{2}$ \\
\hline Magnésio & 25 & $\mathrm{MgCl}_{2} \cdot 6 \mathrm{H}_{2} \mathrm{O}$ \\
\hline Enxofre & 50 & $\mathrm{Na}_{2} \mathrm{SO}_{4}$ \\
\hline Boro & 1 & $\mathrm{Na}_{2} \mathrm{~B}_{4} \mathrm{O} 7 \cdot 10 \mathrm{H}_{2} \mathrm{O}$ \\
\hline Cobre & 2 & $\mathrm{CuCl}_{2} \cdot 2 \mathrm{H}_{2} \mathrm{O}$ \\
\hline Ferro & 5 & $\mathrm{FeCl}_{3} \cdot 6 \mathrm{H}_{2} \mathrm{O}$ \\
\hline Manganês & 2 & $\mathrm{MnCl}_{2} \cdot 6 \mathrm{H}_{2} \mathrm{O}$ \\
\hline Molibdênio & 0.5 & $\mathrm{Na}_{2} \mathrm{MOO}_{4} \cdot 2 \mathrm{H}_{2} \mathrm{O}$ \\
\hline Zinco & 5 & $\mathrm{ZnCl}_{2}$ \\
\hline
\end{tabular}


No plantio foram utilizadas, por vaso, 10 sementes de sorgo granífero, cultivar ICAPAL. Dez dias após a emergência das plântulas, foi efetuado o desbaste, permanecendo cinco plantas/vaso. Os vasos foram irrigados com água destilada, mantendo-se o teor de umide de em torno de $80 \%$ da capacidade máxima de retenção de água.

A colheita da parte aérea foi efetuada aos 50 dias após a emergência das plântulas, sendo colocada em saco de papel, previamente identificado, em seguida posta para secar em estufa com circulação forçada de ar, à temperatura de $65^{\circ} \mathrm{C}$, até que obtivesse peso constante. Os dados foram analisados estatiscamente, tendo sido usado o teste de Tukey, a nível de $5 \%$ para comparação das médias.

\section{RESULTADOS E DISCUSSÃO}

A produção de matéria seca da parte aérea das plantas de sorgo, nos diversos tratamentos e solos, apresentaram comportamento diferenciados (Quadro 3).

Observa-se que, tanto a omissão de fósforo quanto a omissão de nitrogênio, ocasionaram çueda acentuada na produção de matéria seca da parte aérea das plantas, em ambos os solos estudados. Essas respostas a esses nutrientes, deve-se, principalmente, ao baixo teor de fósforo e de matéria orgânica, presentes nos solos em estudo (Quadro 1). Resultados semelhantes; foram obtidos por SANTOS (1980), ao estudar os Regossolos distróficos e Podzólico Vermelho Amarelo de F.reial, Montadas e Mari; ANDRACE FILHC; et alii (1984) err. um Latossolo Vermelho f.marelo distrófico de Areia; DINIZ (1984) em Podzólico Vermelho Amarelo distrófico e Bruno Não-Cálcico, oriundcs de diversas regiōes da Paraỉba.

A omissão de potássio ocasionou queda de produção nos solos estudados ( $A Q C^{\prime}$ e PVd), confirmando os resultados das análises dE solos de fertilidade, onde o teor do nc triente apresentou-se baixo (Quadro 1). DINIZ (1984), tamtém, encontrou resposta fositiva a aplicação de potássio em solos da Paralba, cultivados com c algodoeiro herbáceo, enquanto que MCURA FILHC \& DANTAS (1986) em solos da Paraíba, MARTINS \& BRAGA (1977) em solos do Triângulo Mineiro e VELOSO et alii. (1981) em solos do Vale de Mearim, Maranhão, não encontraram lesposta à aplicação de potássio, possivelmente, por causa do teor adequado de potássio nesses solos, como revelaram as análises de fertilidzde.

Tanto nas Áreias Quartzosas distróficas, como no Podzólico Vermelho Amarelo distrófico, a ausência de calagem e/ou de cálcio ocasionaram redução na produçāo de matéria seca das plantas. Esse fato pode ser atribuido, provavelmente, a presença de Al (Qua- 
QUADRO 3 - Produção de matéria e seca da parte aérea das plantas de sorgo, nos diversos tratamentos e solos (1).

\begin{tabular}{|lcc|}
\hline Tratamento & AQd & PVd \\
\hline Completo & $-34,00 \mathrm{a}$ & $32,00 \mathrm{a}$ \\
Sem B & $35,99 \mathrm{a}$ & $33,24 \mathrm{a}$ \\
Sem Fe & $35,25 \mathrm{a}$ & $32,28 \mathrm{a}$ \\
Sem Mn & $34,48 \mathrm{a}$ & $32,27 \mathrm{a}$ \\
Sem Mg & $32,70 \mathrm{a}$ & $31,38 \mathrm{a}$ \\
Sem S & $31,10 \mathrm{a}$ & $33,20 \mathrm{a}$ \\
Sem Cu & $34,98 \mathrm{a}$ & $30,84 \mathrm{ab}$ \\
Sem Mo & $33,52 \mathrm{a}$ & $30,46 \mathrm{ab}$ \\
Sem Zn & $14,71 \mathrm{bc}$ & $28,47 \mathrm{ab}$ \\
Sem Ca & $17,30 \mathrm{~b}$ & $24,98 \mathrm{~b}$ \\
Sem K & $8,50 \mathrm{~cd}$ & $9,16 \mathrm{c}$ \\
Sem N & $6,67 \mathrm{de}$ & $6,86 \mathrm{c}$ \\
Sem P & $0,64 \mathrm{e}$ & $0,64 \mathrm{~d}$ \\
Testemunha absoluta & $0,30 \mathrm{e}$ & $0,46 \mathrm{~d}$ \\
\hline
\end{tabular}

(1) Em cada coluna, as médias seguidas das mesmas letras não apresentam diferença significativa, ao nível de $5 \%$ de probabilidade, pelo teste de tukey.

dro 1) e ao desbalanceamento da relação $\mathrm{Ca} / \mathrm{Mg}$, provocado pela adição de magnésio. Comportamento igual foi observado por VELOSO et alii (1981) em solos do Maranhão. Percebe-se, também, que apesar das quantidades recomendadas de $\mathrm{CaCO}_{3}$ para ambos os solos serem baixas (Quadro 1), juntamente com a aplicação de $\mathrm{CaCl}_{2}$ (Quadro 2), houve uma grande resposta à aplicação desse tratamento. Esse efeito foi bem mais visivel nas Areias Quartzosas distróficas (Quadro 3), onde a produção caiu cerca de $64 \%$ em relação ao tratamento com adubação completa. Desse modo, podese inferir numa interação entre a calagem ou o cálcio com o fósforo, que mesmo estando presente nesse tratamento (sem Ca), a limitação da calagem ou de cálcio prejudicou a eficiência da adubação fosfatada. 
Quando o zinco fol omitido, ocorreu diminuição na produção de matéria seca da parte aérea das plantas, apenas nas Areias Quartzosas distróficas (Quadro 3). Provavelmente, por causa do baixo teor deste nutriente no solo e ao uso do corretivo da acidez. MARTINS \& BRAGA (1977) não encontraram resposta a aplicação de zinco nos Latossolos do Triângulo Mineiro, no entanto, o teor deste nutriente foi maior nas plantas dos tratamentos sem cálcio $\left(\mathrm{Ca}(\mathrm{OH})_{2}\right)$.

A omissão de magnésio, enxofre, e os micronutrientes (boro, cobre, ferro, manganês e molibdênio) não determinaram decréscimos na produção de matéria seca da parte aérea das plantas nos solos em estudo.

\section{CONCLUSÕES}

Nas Areias Quartzosas distróficas (AQd) foram limitantes, em ordem decrescentes os seguintes nutrientes: fósforo, nitrogênio, potássio, zinco e cálcio; e no Podzólico Vermelho Amarrelo distrófico (PVd), fósforo, nitrogênio, potássio e cálcio. Para maior eficiência dos nutrientes a serem aplicados nesses solos, recomenda-se a prática da calagem.

\section{LITERATURA CITADA}

ANDRADE FILHO, F.C. de, AZEVEDO, J.N. de, MIRANDA, J.de S., AMORIM,N.L. de, SOUZA, N.C., MARTINS,W.B.E. Avaliação da fertilidade de um Latossolo do brejo paraibano através da diagnose por subtração em sorgo granífero em casa de vegetação. Areia: CCA/UFPB, 1984. 55p. (Trabalho apresentado à Disciplina Tópicos Especiais em Fitotecnia do Curso de Pós-Graduação em Produção Vegetal).

CHAMINADE, R. Bilan des trois annees d experimentation en petits veses do vegetation. L'Agronomie tropicale, Paris, v.20, n.11, p. 1.101-1.162, 1965.

DINIZ, M. de S. Avaliação da fertilidade de duas classes de solos cultivados com algodoeiro herbáceo (Gossypium hirsutum L. latifolium Hutch.) no Estado da Paraíba. Areia: Universidade Federal da Paraíba, 1984. 132p. (Dissertação de Mestrado).

EMPRESA DE ASSISTÊNCIA TÉCNICA E EXTENSĀO RURAL DO ESTADO DA PARAIIBA. Sugestōes de adubação para o Estado da Paraíba. João Pessoa: EMATER/PB, 1979. 105p.

KILLIAN, J. e VELLY, J. Diagnostic des carences minerales en vases de vegetation sur quelques sois de Madagascar. L'Agromomie Tropicale, paris, v.19, n.15, p.413-43, 1984. 
MARTINI, J.A. Caracterizacion del estado nutricional de lo principales "Latossolos" de Costa Rica, mediante a técnica del elemento faltante en el envernadera. Turrialba, Costa Rica, v.19, n.3, p.394-408, 1969.

MARTINS, O. E BRAGA, J.M. Caracterização da fertilidade de cinco Latossolos sob vegetação de cerrado, no Triangulo Mineiro. Rev. Ceres, Viçosa, v.24, n.136, p.586-607, 1977.

MOURA FILHO, G. e DANTAS, J.P. Avaliação da fertilidade de duas classes de solos do Estado da Paraíba, através da diagnose por subtração em sorgo granífero. In.: CONGRESSO BRASILEIRO DE INICIAÇÃO CIENTÍFICA EM CIÊNCIAS AGRÁRIAS, VI, 1986, Lages. Anais ... (No prelo).

SANTOS, F.B. dos. Levantamento do estado atual da fertilidade de duas classes de solos da Paraíba. Areia: Universidade Federal da Paraíba, 1980. 22p. (Dissertação para Graduação em Agronomia).

SHENKEL, G.S., BAHERLE, P.V., FLOODY, T.A., GAYARDO, M.M. Exploracion de deficiências nutritivas con suelos en macetas. I. Experiencia preliminar. Agric. Técnica, Santiago, v.30, n.4,179-193, 1970.

VELOSO, C.A.C., MARAL, F. de A.L. do, BRAGA, J.M., ALVAREZ V.. V.H. Avaliação da fertilidade de quatro solos do Vale de Mearim, Maranhão, para a cultura do arroz (Oryza sativa (L.) cultivar "IAC-1246". Rev. Cres, Viçosa, v.28, n.160, p.607-613, 1981.

VETTORI, L. Métodos de análises de solo. Rio de Janeiro: EPE, Ministério da Agricultura, 1969. 24p. (Ministério da Agricultura, 7). 